\title{
Bohrer stumpf? Nein - oft nur verstopft!
}

Dankward Höntzsch

Häufig wird über stumpfe Bohrer geschimpft!

Oft sind aber nur die Nuten des Bohrers mit Knochenmehl verstopft ( $\triangleright$ Abb. 1).

Dann hilft, einfach den Bohrer herauszuziehen - mit oder ohne Rotation ist egal - und die Nuten zu säubern, das geht manchmal sogar von selbst oder mit kurzem Wischen in Richtung der Spirale des Bohrers. Dann bohrt der gleiche Bohrer wieder gut.

Der gleiche Effekt entsteht, wenn die OP-Assistenz den Bohrer wechselt. In Wirklichkeit muss er gar nicht besser sein, sondern nur frei!

Das Verstopfen der Nuten passiert besonders bei dicken Knochen und langen Strecken. Anfällig für das Zusetzen der Nuten sind Knochen in Nähe von Pseudarthrosen, bei jugendlichen Knochen oder nach mehrfachen Reoperationen.

Auf jeden Fall gilt die Regel, dass man immer das Gefühl haben muss, dass der Bohrer arbeitet und die Bohrung fortschreitet. Wenn dies nicht der Fall ist, entsteht nur Hitze durch stumpfen Bohrer oder eben wie beschrieben durch verstopfte Nuten, die nur frei gemacht werden müssen.

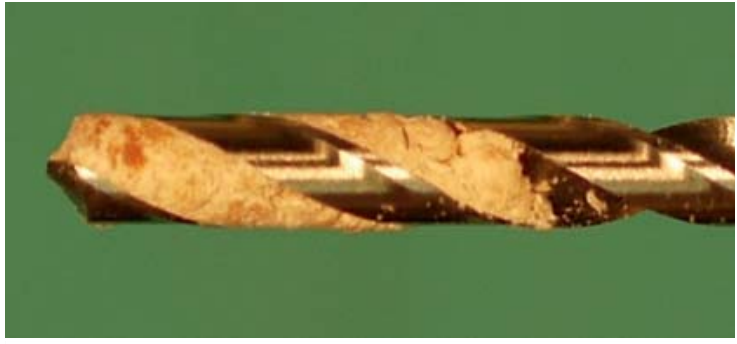

- Abb. 1 Beispiel von verstopften Nuten an einer Bohrerspitze. So bohrt ein Bohrer nicht gut und täuscht vor, dass er stumpf ist. Bei bestimmten Konstellationen und Knochenarten bäckt das Knochenmehl so zusammen, dass der Abtransport in den Nuten unterbleibt!

\section{Korrespondenzadresse}

\section{Dankward Höntzsch}

hoentzsch@t-online.de

\section{Bibliografie}

DOI https://doi.org/10.1055/a-0652-0960

Online-publiziert 05.10.2018| OP-JOURNAL 2018; 34: 328

(C) Georg Thieme Verlag KG Stuttgart · New York

ISSN 0178-1715 